\title{
E-COMMERCE UNTUK MENINGKATKAN PENJUALAN BIJI KOPI PADA ANDALAN COFFEE
}

\author{
Gabriel Mohara ${ }^{1)}$, Grace Gata ${ }^{2)}$ \\ ${ }^{1}$ Sistem Informasi, Fakultas Teknologi Informasi, Universitas Budi Luhur \\ ${ }^{1,2} \mathrm{Jl}$. Raya Ciledug, Petukangan Utara, Kebayoran Lama, Jakarta Selatan 12260 \\ E-mail : andrialfian83@gmail.com ${ }^{1)}$, grace.gata@budiluhur.ac.id ${ }^{2)}$
}

\begin{abstract}
Abstrak
Permasalahan Andalan Coffee adalah informasi biji kopi sulit diketahui oleh customer, stok barang dan pencatatan alamat pengiriman masih konvensional, belum ada pencatatan penjualan biji kopi dan pemesanan produk. Peneliti melakukan pendekatan masalah dengan metode wawancara, observasi, analisa dokumentasi dan studi kepustakaan sehingga mengetahui data dan menganalisa proses bisnis yang ada menggunakan UML (Unified Modeling Languange) seperti Activity Diagram, Use Case Diagram, Class Diagram dan System Sequence Diagram. Manfaat dari penelitian yaitu membantu dalam pemasaran biji kopi dan pengelolaan barang lebih terstruktur. Dengan E-Commerce yang telah dibuat oleh peneliti pada Andalan Coffee, maka dapat membantu memperluas informasi produk, adanya fitur packing slip dapat mengurangi kesalahan alamat pengiriman, laporan stock dapat mencegah data hilang, laporan orders membantu admin mengetahui pesanan, dan laporan sales sebagai evaluasi untuk pemilik.
\end{abstract}

Kata kunci: E-Commerce, Andalan Coffee, Biji Kopi.

\section{PENDAHULUAN}

Seiring dalam perkembangan dunia bisnis saat ini E-Commerce merupakan suatu kebutuhan untuk meningkatkan serta memenangkan persaingan bisnis dan penjualan produk produk. Pada proses penggunaan E-Commerce kegiatan jual beli maupun pemasaran lebih efisien dimana penggunaan $E$ Commerce tersebut akan memperlihatkan adanya kemudahan bertransaksi, pengurangan biaya dan mempercepat proses transaksi. Kualitas transfer data juga menjadi lebih baik daripada menggunakan proses manual, dimana tidak dilakukannya entry ulang yang memungkinkan terjadinya human error. [1]

Peneliti mengadakan riset di Andalan Coffee yang beralamat di wisma raharja cilandak barat Jakarta Selatan, kedai ini merupakan sebuah unit dagang yang bergerak di bidang penjualan kopi di perkantoran kota Jakarta.

Permasalahan yang dihadapi oleh Andalan Coffee adalah informasi biji kopi pada Andalan Coffee sulit diketahui oleh customer, stok barang masih konvensional menggunakan papan tulis sehingga data mudah hilang, Pencatatan alamat pengiriman masih konvensional sehingga mudah terjadi kesalahan data, belum ada pencatatan penjualan biji kopi secara detail sesuai dengan jenis biji kopi dan pencatatan pemesanan produk untuk penjual.

Oleh karena permasalahan tersebut, maka Peneliti memberikan solusi untuk membuat ECommerce sebagai sarana penjualan dan promosi dengan memanfaatkan internet. Dengan harapan bahwa masyarakat lebih mengenal tentang Andalan Coffee dan juga produknya.

Website merupakan kumpulan halamanhalaman yang digunakan untuk menampilkan informasi teks, gambar diam ataupun gerak, animasi, suara, atau gabungan dari semuanya, baik yang bersifat statis maupun dinamis yang membentuk satu rangkaian bangunan yang saling terhubung, yang masing-masing dihubungkan dengan jaringanjaringan halaman.[2]

Model bisnis kanvas adalah model bisnis yang dikembangkan oleh Alexander Osterwalder dan Yves Pigneur pada bukunya yang berjudul Business Model Generation.[3] Model bisnis canvas ini memiliki sembilan (9) elemen (blocks) yang saling berkaitan.

Interaction Flow Modeling Language (IFML) adalah bahasa pemodelan yang sangat terinspirasi oleh WebML dan mewakili generalisasi dari domain web untuk aplikasi generic pemodelan front-end. IFML dirancang untuk mengekspresikan konten, interaksi pengguna, dan mengatur perilaku dari front-end aplikasi perangkat lunak. [4]

System Sequence Diagram (SSD) adalah diagram yang digunakan untuk mendeskripsikan aliran informasi input dan output dari sistem yang terotomatisasi. System Sequence Diagram (SSD) menjelaskan data yang masuk dan data yang keluar dan mengidentifikasi interaksi antara aktor dalam sistem.[5]

WooCommerce adalah plugin Wordpress yang sangat populer, plugin ini menyulap Wordpress menjadi platform E-Commerce yang handal. Plugin ini memiliki kemampuan dan banyak fitur yang 
keren, karena WooCommerce berjalan di atas Wordpress, yang notabenenya salah satu Content Management System (CMS) terbaik, hal ini membuat WooCommerce sangat fleksibel dan relatif mudah untuk disesuaikan.[6]

\section{PENELITIAN SEBELUMNYA}

Penelitian yang dilakukan oleh Filbert dan Astri Wulandari berjudul Analisa Penerapan Ecommerce Pada UKM Keykey Frozen Food Cimahi yang dipublikasikan pada E-Proceeding of Applied Science. Penelitian ini mengenai peran E-Commerce yang berfungsi sebagai media promosi dan jual beli elektronik, serta mengetahui kendala yang dihadapi dalam implementasi E-Commerce. Keykey Frozen Food merupakan sebuah usaha makanan yang bergerak dibidang makanan beku dan olahan ice cream. Masalah yang dihadapi Keykey Frozen yaitu sistem promosi dalam pemasaran produk masih dilakukan secara konvensional seperti mendatangi toko-toko untuk yang ingin menjadi pengecer atau mencari orang untuk menjadi agennya. Namun belum mendapatkan hasil yang maksimal disebabkan oleh kekurangan pada toko ini adalah hanya menjual kepada pengecer dan Agen saja. Hasil tersebut disebabkan oleh kekurangan modal, sumber daya dan pengetahuan akan E-Commerce. Berdasarkan hasil penelitian, maka peneliti menerapkan penjualan berbasis E-Commerce pada Keykey Frozen yang bertujuan agar toko dapat dikenal lebih luas oleh masyarakat serta dapat menginformasikan secara terperinci kepada pelanggan dan membantu UKM Keykey Foods dalam memperkembangkan usaha yang lebih optimal serta dapat bersaing dengan UKM sejenis. Jenis penelitian yang dilakukan adalah kualitatif dan deskriptif. Sumber data yang diperoleh yaitu melalui sumber data primer dan sumber data skunder. Teknik yang dilakukan oleh peneliti adalah menggunakan observasi, wawancara dan dokumentasi. [7]

Penelitian yang dilakukan oleh Shabur Miftah, Heru Susilo dan Riyadi berjudul Implementasi ECommerce Sebagai Media Penjualan Online (Studi Kasus Pada Toko Pastbrik Kota Malang) yang dipublikasikan pada jurnal Administrasi Bisnis. Penelitian ini menjelaskan tentang manfaat adanya penerapan E-Commerce dalam perkembangan dunia bisnis, yang merupakan suatu kebutuhan untuk meningkatkan serta memenangkan persaingan bisnis dalam memasarkan produk-produk. Penelitian ini mengambil studi kasus pada toko Pastbrik kota Malang dengan menggunakan metode teknik pengumpulan data seperti observasi, wawancara dan dokumentasi. Hasil penelitian menggunakan implementasi E-Commerce dengan menggunakan software opencart pada toko Pastbrik Malang.
Sistem penjualan yang digunakan oleh toko Pastbrik saat ini masih menggunakan sistem konvensional atau offline dimana pembeli untuk mendapatkan barang yang diinginkan harus datang langsung ke toko. Dari hasil penelitian, peneliti melakukan pengkajian implementasi E-Commerce dengan menggunakan software opencart pada toko Pastbrik yang bertujuan untuk membantu mengurangi biaya yang dikeluarkan serta dapat menyampaikan informasi secara detail mengenai produk maupun harga spesial yang diberikan kepada customer secara online dan memudahkan proses transaksi tanpa harus datang ke toko secara langsung sehingga dapat bersaing dengan toko yang sejenis dan mendapatkan hasil yang lebih maksimal. [8]

Penelitian yang dilakukan oleh Dedi, Siti Maisaroh Mustofa, dan Suhartono berjudul Impementasi E-Commerce Toko Prayoga Sport Berbasis Content Management System (CMS) Joomla Modules VirtueMart yang dipublikasikan pada jurnal Sisfotek Global. Prayoga Sport yang berlokasi di daerah Cikupa, Kecamatan Tangerang adalah salah satu toko yang menjual berbagai jenis sepatu dengan mengandalkan pembeli yang langsung ke toko. Permasalahan yang terjadi adalah toko Prayoga Sport kurang dikenal karena media promosi dan penjualan yang dipakai masih bersifat konvensional.Tujuan pada penelitian ini untuk memasarkan dan melakukan transaksi berbasis online dengan menerapkan sistem E-Commerce. Manfaat yang diharapkan oleh peneliti yaitu membantu melakukan pemasaran dan mempromosikan produk yang dijual di toko Prayoga Sport serta meningkatkan penjualan dan pelayanan kepada customer, sehingga toko Prayoga Sport menjadi lebih terkenal dan memiliki banyak pelanggan. Berdasarkan referensi penelitian tersebut, bahwa pada tugas. [9]

\section{METODE PENELITIAN}

\subsection{Kerangka Pemikiran}

Pada Gambar 1 merupakan kerangka pemikiran yang berisikan masalah yang ada pada penelitian, maka diperlukan pendekatan masalah dengan metode wawancara, observasi, analisa dokumentasi dan studi kepustakaan sehingga dapat mengetahui data dan menganalisa proses bisnis yang ada menggunakan UML. Untuk memecahkan permasalahan yang ada pada Andalan Coffee maka dibuatkan sebuah E-Commerce untuk meningkatkan penjualan produk pada Andalan Coffee. 


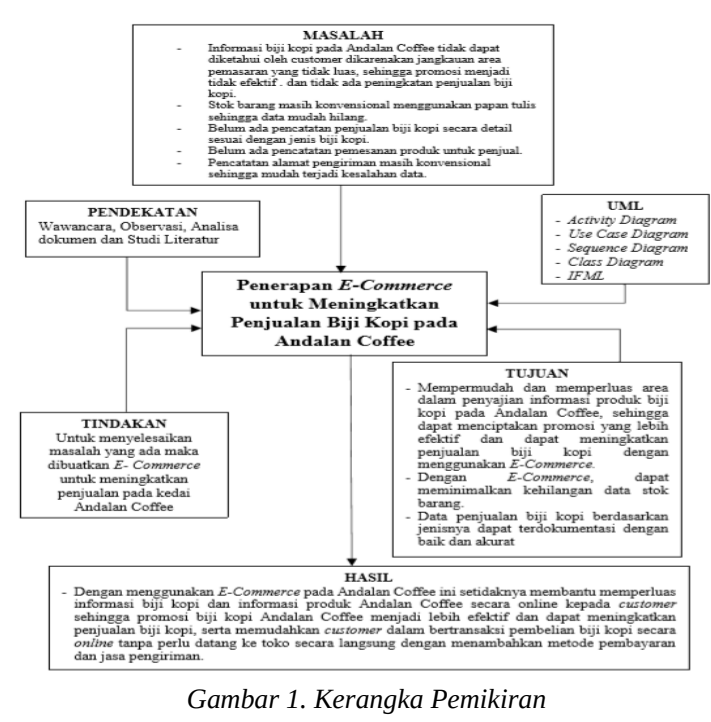

\subsection{Teknik Pengumpulan Data}

Teknik pengumpulan data merupakan faktor penting dalam penelitian. Data yang terkumpul akan digunakan sebagai bahan analisis. Untuk memperoleh informasi mengenai hasil dari penelitian ini, diperlukan adanya sumber data yang merupakan subjek darimana berasal atau diperoleh. Sumber pengumpulan data yang digunakan dalam penelitian yaitu :

a. Wawancara

Wawancara ini dilakukan dalam rangka mendapatkan data dan informasi. Pada tahapan ini, Peneliti berkomunikasi dan bertanya langsung dengan pemilik Andalan Coffee, pada 21 Maret 2019, bagaimana proses penjualan pada Andalan Coffee, mulai dari pemesanan, data produk, laporan penjualan, dan cara mempromosikan produk.

b. Observasi

Observasi dilakukan dengan melihat langsung proses penjualan secara langsung di Kedai dan promosi yang dilakukan masih secara konvensional. Observasi dilakukan pda 2 April 2019.

c. Teknik Dokumentasi

Analisa dokumen dilakukan untuk menganalisa dokumen berjalan agar diperoleh informasi yang sesuai dengan kebutuhan sistem yang dibuat.

d. Studi Literatur

Studi literatur dilakukan untuk mengetahui penelitian terdahulu mengenai topik yang sama dengan topik yang ingin ditulis. Peneliti mendapatkan referensi dari berbagai sumber tertulis, baik berupa bukubuku, jurnal, artikel serta referensi yang berkaitan dengan masalah yang sedang diteliti.

4. HASIL DAN PEMBAHASAN

4.1. Business Model Canvas Andalan Coffee

Berikut gambar dari Business Model Canvas Andalan Coffee :

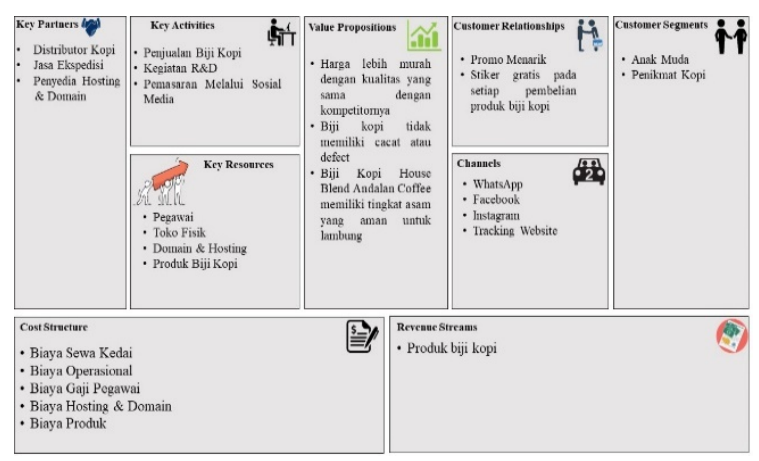

Gambar 2. Business Model Canvas Andalan Coffee

Seperti terlihat pada gambar 2, secara umum model bisnis kanvas adalah untuk menggambarkan lingkungan keseluruhan dari setiap perusahaan terdiri dari bagian sembilan (9) :

a. Customer Segments

Customer Segments adalah pihak yang akan membeli produk Andalan Coffee. Saat ini kopi salah satu bahan pembicaraan yang paling sering digunakan oleh anak muda sehingga anak muda menjadi salah satu segmen dari Andalan Coffee dan yang selanjutnya adalah para penikmat kopi karena penikmat kopi sering mencoba kopi secara acak tanpa melihat brand kopi tersebut.

b. Value Propositions

Value Propositions merupakan nilai lebih yang ditawarkan oleh Andalan Coffee kepada pelanggan. Biji kopi Andalan Coffee memiliki harga lebih murah dan kualitas yang sama dengan kompetitor, biji kopi Andalan Coffee termasuk grade premium sehingga pada setiap biji kopi Andalan Coffee tidak memiliki cacat atau defect. Biji kopi house blend Andalan Coffee memiliki tingkat asam yang aman bagi lambung.

c. Channels

Proses komunikasi ke customer yang dilakukan oleh Andalan Coffee yaitu melalui whatsapp jika customer memiliki pertanyaan tentang produk ataupun jasa Andalan Coffee dan promosi dilakukan melalui instagram dan facebook. Tracking Website digunakan E-Commerce untuk mempermudah customer dalam melacak produknya.

d. Customer Relationships

Teknik yang digunakan Andalan Coffee untuk meningkatkan minat dan hubungan yang lebih baik dengan customer yaitu dengan memberikan promosi 
seperti memberikan diskon pada hari raya besar ataupun memberikan diskon pada produk baru. Teknik lainnya yaitu memberikan stiker gratis pada setiap pembelian biji kopi Andalan Coffee.

\section{e. Revenue Streams}

Arus pendapatan yang dihasilkan oleh ECommerce Andalan Coffee yaitu dari penjualan produk biji kopi.

\section{f. Key Resource}

Sumber daya yang dimiliki oleh Andalan Coffee adalah pegawai, toko fisik, produk biji kopi, domain dan hosting.

g. Key Activities

Aktivitas utama yang dilakukan oleh Andalan Coffee yaitu penjualan biji kopi, Kegiatan $R \& D$ untuk mengembangkan produk dan kemasan produk dam pemasaran melalui media sosial.

h. Key Partnership

Mitra utama dari Andalan Coffee adalah distributor kopi sebagai penyedia biji kopi, jasa ekspedisi,dan penyedia hosting \& domain untuk ECommerce.

i. Cost Structure

Struktur biaya Andalan Coffee meliputi sewa kedai, operasional, gaji pegawai, pembelian produk biji kopi, hosting \& domain.

\subsection{Activity Diagram Usulan}

a. Activity Diagram Usulan Pesanan

Berikut gambar proses bisnis usulan pesanan Andalan Coffee menggunakan activity diagram :

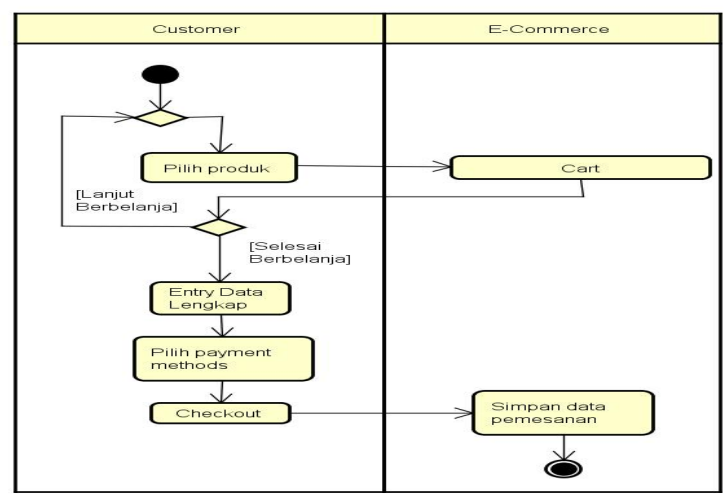

Gambar 3. Activity Diagram Usulan Pesanan

Seperti terlihat pada gambar 3, customer dapat memilih produk yang diinginkan dan memasukannya ke keranjang belanja, jika Customer masih ingin berbelanja maka Customer memilih produk yang ingin dibeli tapi jika Customer sudah selesai berbelanja maka produk akan dimasukan kedalam Cart. Lalu Customer harus mengentrykan data yang dibutuhkan oleh website, kemudian Customer memilih metode pembayaran dan mengklik tombol checkout.

b. Activity Diagram Usulan Pembayaran
Berikut gambar proses bisnis usulan pembayaran Andalan Coffee menggunakan activity diagram :

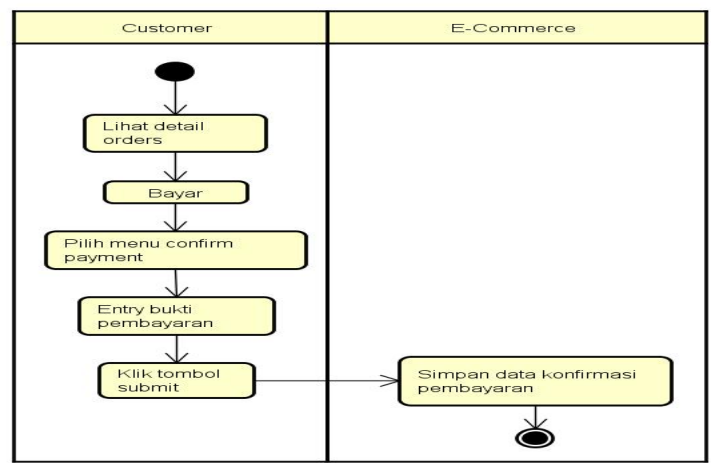

Gambar 4. Activity Diagram Usulan Pembayaran

Seperti terlihat pada gambar 4, Customer melakukan pembayaran berdasarkan pada data yang ditampilkan pada detail pesanan. Lalu Customer melakukan konfirmasi pembayaran pada menu Confirm Payment dan entry bukti pembayaran, kemudian mengklik tombol Submit.

c. Activity Diagram Usulan Laporan Sales

Berikut gambar proses bisnis usulan laporan Sales Andalan Coffee menggunakan Activity Diagram:

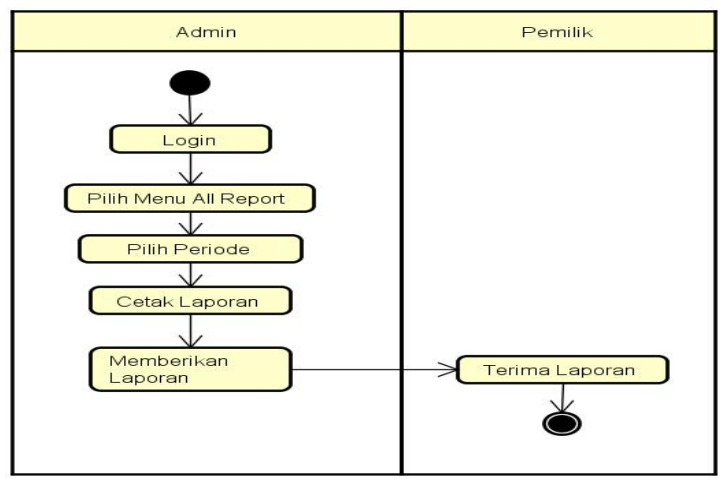

Gambar 5. Activity Diagram Usulan Laporan Sales

Seperti terlihat pada gambar 5, Admin mencetak laporan Sales dan diserahkan kepada pemilik kedai.

\subsection{Use Case Diagram}

a. Use Case Diagram Entry Pesanan

Berikut adalah gambar Use Case Diagram entry Pesanan :

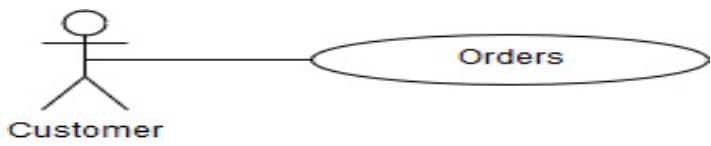

Gambar 6. Use Case Diagram Entry Pesanan 
Seperti terlihat pada gambar 6, Use Case Diagram Entry Pesanan terdiri dari 1 aktor yaitu Customer yang berelasi dengan Use Case Orders.

b. Use Case Diagram Konfirmasi Pembayaran

Berikut adalah gambar Use Case Diagram konfirmasi pembayaran:

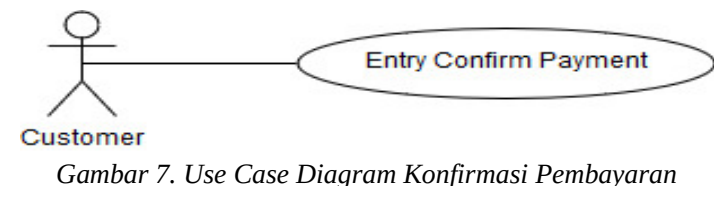

Seperti terlihat pada gambar 7, Use Case Diagram konfirmasi pembayaran terdiri dari 1 aktor yaitu Customer yang berelasi dengan Use Case Confirm Payment.

c. Use Case Diagram Laporan

Berikut adalah gambar Use Case Diagram Laporan:

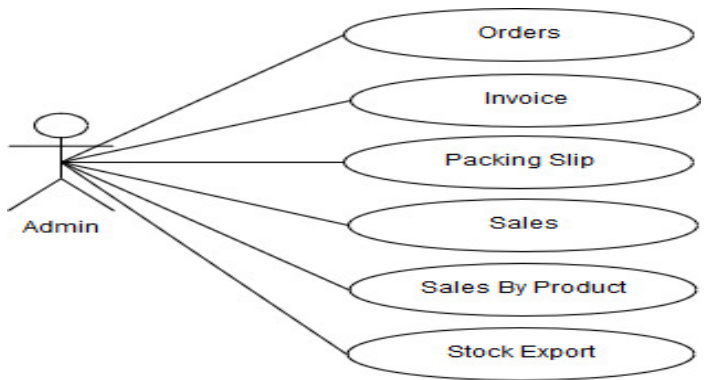

Gambar 8. Use Case Diagram Laporan

Seperti terlihat pada gambar 8, Use Case Diagram Laporan terdiri dari 1 aktor yaitu Admin. Admin berelasi dengan 6 use case yaitu Orders, Invoice, Packing Slip, Sales, Sales By Product, dan Stock Export.

\subsection{Tampilan Layar}

a. Tampilan Checkout

Berikut adalah gambar dari Tampilan Checkout:

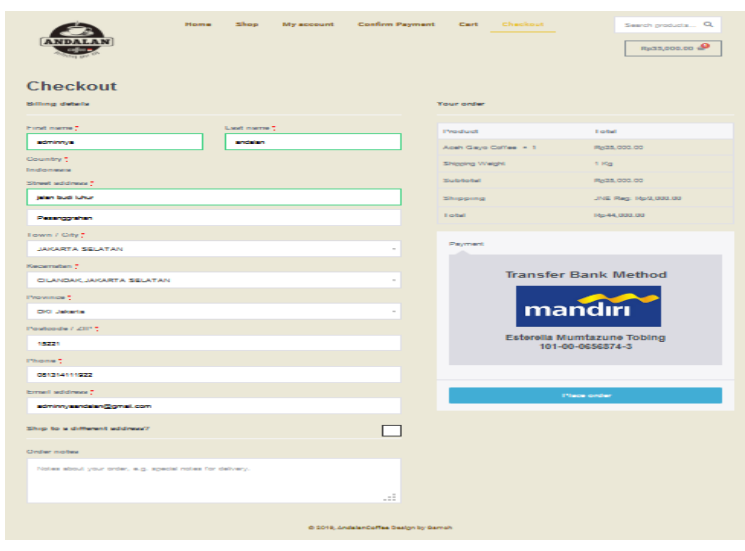

Gambar 9. Tampilan Checkout
Seperti terlihat pada gambar 9 adalah tampilan berupa form untuk menginputkan data alamat pengiriman, nomor telepon, email dan catatan jika Customer ingin memberi catatan untuk Admin. Menu checkout juga menampilkan informasi tentang biaya pengiriman sesuai dengan alamat yang telah diinputkan dan informasi pembayaran. Jika data sudah sesuai maka tekan tombol place order sehingga data pesanan tersimpan oleh E-Commerce.

\section{b. Tampilan Confirm Payment}

Berikut adalah gambar dari Tampilan Confirm Payment :

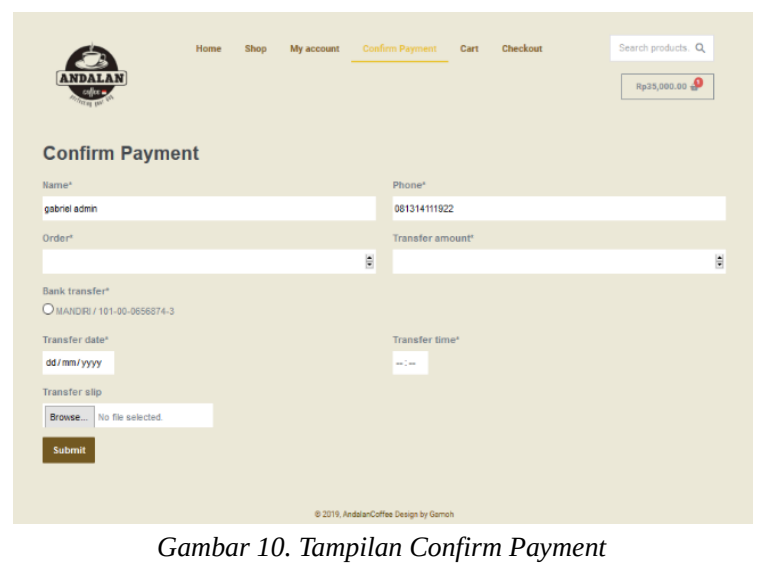

Seperti terlihat pada gambar 10 adalah tampilan berupa form untuk menginputkan data pembayaran yang terdiri dari Name, Phone, Order, Transfer amount, Bank Transfer, Transfer Date, Transfer Time, Transfer Slip. Untuk mengupload bukti pembayaran dalam bentuk foto maka tekan tombol Browse dan akan muncul pop up windows untuk memilih file foto. Jika sudah lengkap maka tekan tombol submit agar confirm payment dapat tersimpan pada E-Commerce.

c. Tampilan Sales

Berikut adalah gambar dari Tampilan Sales:

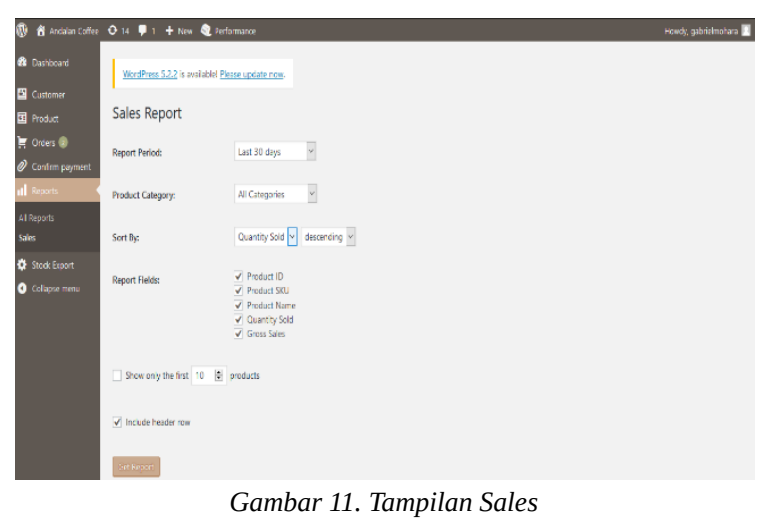

Seperti terlihat pada gambar 11 adalah tampilan berupa form untuk mengexport data sales. Admin 
dapat memilih periode laporan, kategori produk, urutan laporan, fields yang diperlukan, produk teratas sesuai nomor urutan dan header setiap kolom yang akan diexport. Untuk mengexport yaitu tekan tombol Get Report maka data akan terdownload dalam bentuk excel.

\subsection{IFML}

a. Entry Orders

Berikut adalah gambar dari IFML Entry Orders:

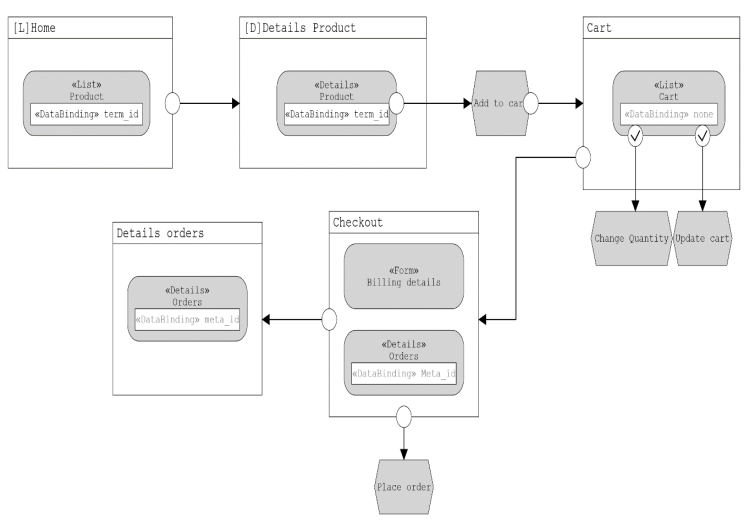

Gambar 12. Entry Orders

Seperti terlihat pada gambar 12 adalah halaman home yang menampilkan list product dan pada saat Customer memilih produk maka E-Commerce akan menampilkan halaman details product. Customer menekan tombol add to cart untuk ditambahkan pada halaman cart, jika customer ingin menambahkan jumlah produk makan tekan tombol change quantity lalu tekan tombol update cart. Jika produk sudah sesuai maka memilih checkout dan ECommerce akan menampilkan halaman checkout, lalu Customer mengisi form billing details dan tekan tombol place order sehingga data akan tersimpan pada halaman details orders.

b. Entry Confirm Payment

Berikut adalah gambar dari IFML Entry Confirm Payment :

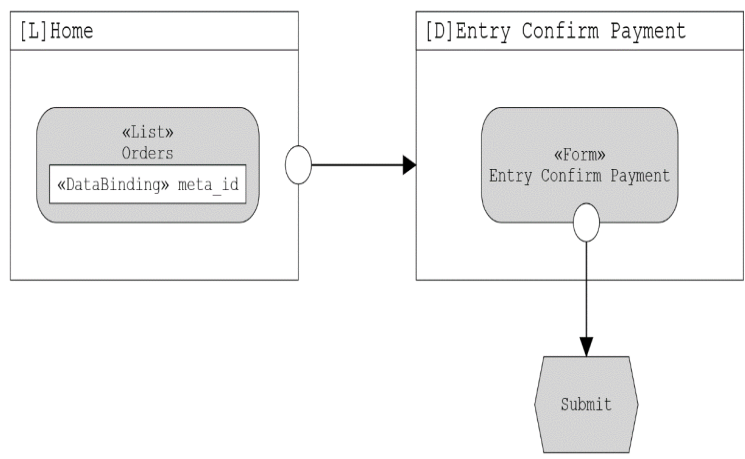

Gambar 13. Entry Confirm Paymet
Seperti terlihat pada gambar 13 adalah halaman home lalu Customer memilih menu Entry Confirm Payment dan E-Commerce akan menampilkan halaman berupa form Entry Confirm Payment. Jika sudah diisi maka customer menekan tombol submit dan data Entry Confirm Paymen akan tersimpan pada E-Commerce.

c. Laporan Sales

Berikut adalah gambar dari IFML Laporan Sales:

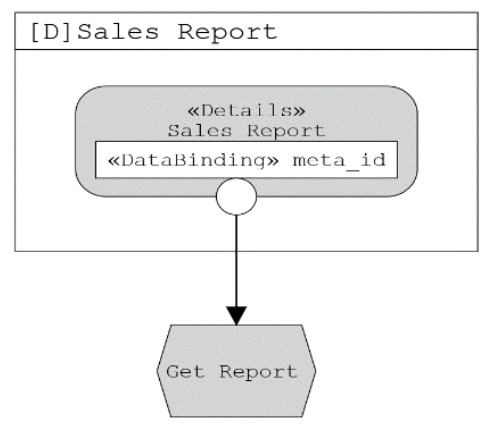

Gambar 14. Laporan Sales

Seperti terlihat pada gambar 14 adalah halaman Sales Report yang berisi detail dari laporan sales dan Admin dapat mengexport laporan sales dengan menekan tombol get report, lalu laporan akan terexport dalam bentuk excel.

\subsection{System Sequence Diagram}

a. System Sequence Diagram Entry Orders

Berikut adalah gambar dari System Sequence Diagram Entry Orders :

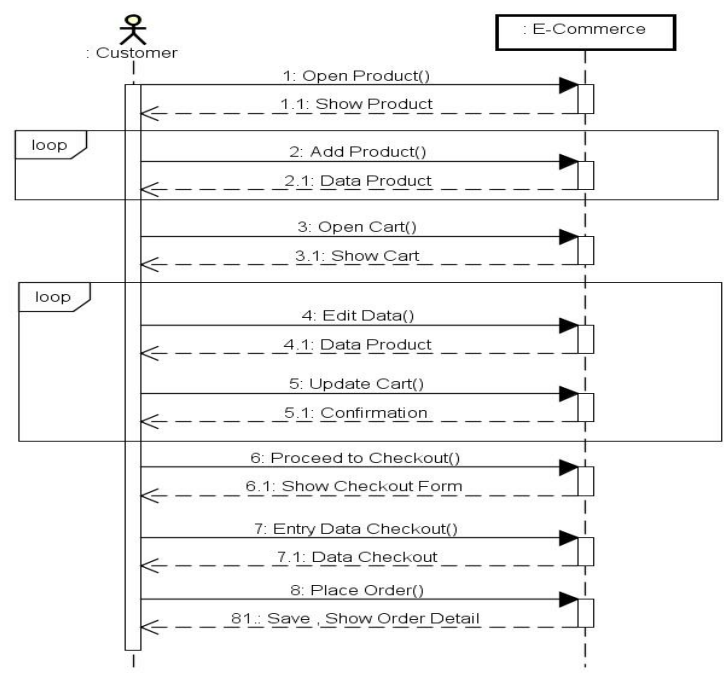

Gambar 15. System Sequence Diagram Entry Orders

Seperti terlihat pada gambar 15, customer membuka produk dan produk ditampilkan oleh $E$ Commerce. Customer dapat menambahkan produk pada cart secara berulang tanpa harus berpindah 
halaman. Customer membuka cart dan E-Commerce menampilkan cart. Pada halaman cart, customer dapat mengedit data dan mengupdate data secara berulang. Customer menekan tombol Proceed to Checkout dan E-Commerce menampilkan Checkout Form. Customer mengentrykan data checkout dan menekan tombol place order, maka E-Commerce menyimpan data order dan menampilkan order detail.

b. System Sequence Diagram Entry Confirm Payment

Berikut adalah gambar dari System Sequence Diagram Entry Confirm Payment :

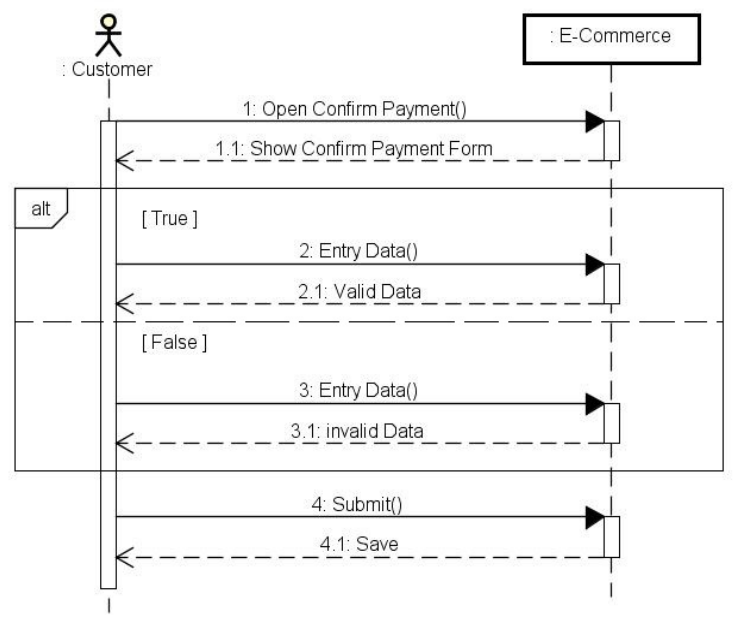

Gambar 16. System Sequence Diagram Entry Confirm Payment

Seperti terlihat pada gambar 16, customer membuka confirm payment dan E-Commerce menampilkan confirm payment form. Customer mengentrykan data confirm payment, jika data yang dientry benar maka E-Commerce menyatakan data tersebut valid dan jika tidak benar maka $E$ Commerce tidak valid. Jika data valid maka customer dapat menekan tombol submit dan data confirm payment akan disimpan oleh E-Commerce.

c. System Sequence Diagram Laporan Sales

Berikut adalah gambar dari System Sequence Diagram Laporan Sales :

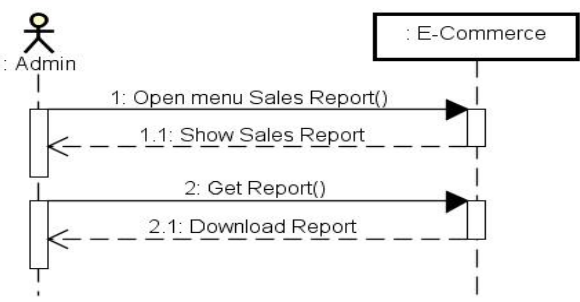

Gambar 17. System Sequence Diagram Laporan Sales

Seperti terlihat pada gambar 17, Admin membuka menu Sales Report dan E-Commerce menampilkan Sales Report. Admin tekan tombol Get
Report dan E-Commerce mendownload Laporan Sales.

\subsection{Hasil Cetakan}

a. Hasil Cetakan Packing Slip

Berikut adalah gambar dari Hasil Cetakan Packing Slip :

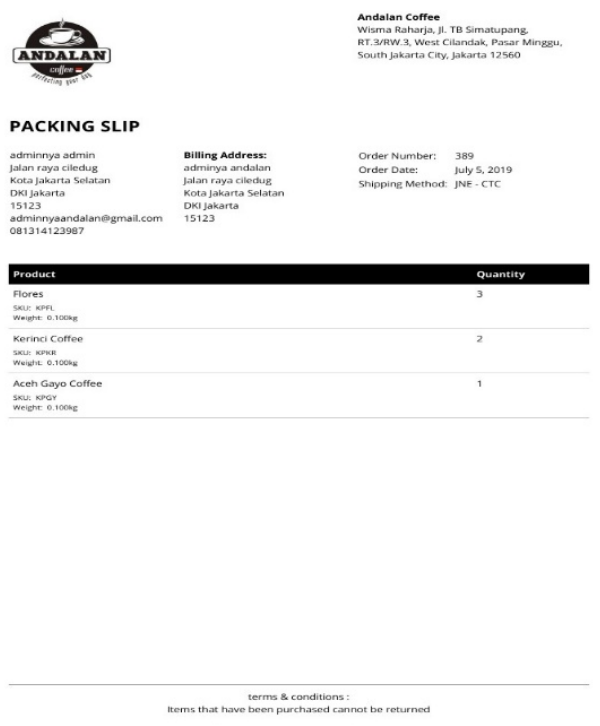

Gambar 18. Hasil Cetakan Packing Slip

Seperti terlihat pada gambar 18 adalah Hasil Cetakan Packing Slip yang berisi data alamat Andalan Coffee, billing address, Order Number, Order Data, Shipping Method yang dipilih oleh customer, Product berisi detail detail produk dan quantity dari setiap produk yang dipesan. Kelebihan fitur dari gambar 18 bagi Andalan Coffee dapat mencetak banyak Orders dan juga satuan dan manfaat yang didapatkan yaitu Andalan Coffee tidak perlu menulis alamat pengiriman secara konvensional.

b. Hasil Cetakan Laporan Sales

Berikut adalah gambar dari Hasil Cetakan Laporan Sales :

\begin{tabular}{|c|c|c|c|c|}
\hline Product ID & Product SKU & Product Name & Quantity Sold & Gross Sales \\
\hline 340 & KPFL & Flores & 5 & 175000 \\
\hline 188 & KPGY & Aceh Gayo Coffee & 3 & 105000 \\
\hline 331 & KPKR & Kerinci Coffee & 2 & 70000 \\
\hline 334 & KPCW & Ciwidey Coffee & 1 & 35000 \\
\hline \multicolumn{5}{|c}{ Gambar 19. Hasil Cetakan Laporan Sales }
\end{tabular}

Seperti terlihat pada gambar 19 adalah Hasil Cetakan Laporan Sales terdiri dari Product ID, Product SKU, Product Name, Quantity Sold yaitu jumlah yang terjual pada satu produk, Gross Sales adalah total penjualan pada satu produk. Kelebihan fitur pada gambar 19 yaitu dapat memilih kolom apa saja yang akan dicetak dan memiliki manfaat bagi 
pemilik untuk mengetahui penjualan pada setiap produk.

\section{KESIMPULAN}

Kesimpulan yang dapat diambil dari penelitian yang telah dilakukan oleh Peneliti adalah:

a. Dengan menggunakan E-Commerce pada Andalan Coffee ini setidaknya membantu memperluas informasi biji kopi dan informasi produk Andalan Coffee secara online kepada customer, serta memudahkan customer dalam bertransaksi pembelian biji kopi secara online tanpa perlu datang ke toko secara langsung dengan menambahkan metode pembayaran dan jasa pengiriman, sehingga promosi biji kopi menjadi lebih efektif dan dapat meningkatkan penjualan biji kopi pada Andalan Coffee.

b. Berkat adanya fitur packing slip, Admin dapat langsung mencetak alamat pengiriman tanpa perlu menulis secara tradisional sehingga dapat menghindari kesalahan data alamat pengiriman.

c. Dengan adanya fitur laporan Stock, maka data stok barang tidak akan mudah hilang.

d. Dengan fitur Orders dan laporan Orders, Admin dapat dengan mudah mengetahui pesanan customer dan dapat meminimalkan kesalahan barang pesanan.

e. Berkat adanya laporan sales by product dan laporan sales, pemilik dapat mengetahui produk yang paling laku terjual dan dapat mengetahui jumlah penjualan produk.

\section{DAFTAR PUSTAKA}

[1] Maulana, Shabur Miftah., Susilo, Heru., \& Riyad. Implementasi E-Commerce Sebagai Media Penjualan Online (Sudi Kasus Pada Toko Pastbrik Kota Malang), Jurnal Administrasi Bisnis, 29(1), pp.1-9. 2015.

[2] Bekti, Bintu Humairah. Mahir Membuat Website dengan Adobe Dreamweaver CS6, CSS dan JQuery, Yogyakarta: ANDI. 2015.

[3] Anggoro, Dimas., Praptono , Budi., \& Aurachman, Rio. Pengembangan Model Bisnis Sandiwara Store Dengan Menggunakan Pendekatan Business Model Canvas. E-Proceeding of Engineering, 3(2), pp. 3058-3065. 2016.

[4] Suryanto, Steven P., Pattiasina, Timothy J., \& Soetarmono, Anggya. Perancangan dan Pengembangan Toko Online dengan Metode Interaction Flow Modeling Language (Studi Kasus Toko Winata). Teknika, 6(1), pp 9-18. 2017.

[5] Satzinger, John.W., Jackson, Robert. B., \& Burd, Stephen. D, Introduction To Systems Analysis And Design: An Agile, Iterative Approach, 6th ed. USA: Course Technology. 2012.

[6] Oley, Enrico., Sentinuwo, Eng Steven R.,\& Sinsuw, Alicia A.E. Sistem Pemesanan Makanan Dan
Minuman Berbasis Website (Studi Kasus Taipan Restoran). E-Journal Teknik Elektro dan Komputer, 5(4), pp. 89-101. 2016.

[7] Filbert, Marcel., Wulandari, Astri. Analisa Penerapan E-Commerce Pada UKM Keykey Frozen Food Cimahi Tahun 2018. E-Proceeding of Applied Science, 4(3), pp. 765-779. 2017.

[8] Maulana, Shabur Miftah., Susilo, Heru., \& Riyadi. Implementasi E-Commerce Sebagai Media Penjualan Online (Sudi Kasus Pada Toko Pastbrik Kota Malang). Jurnal Administrasi Bisnis, 29(1), pp 1-9. 2015.

[9] Dedi., Mustofa, Siti Maisaroh.,\& Suhartono. Impementasi E-Commerce Toko Prayoga Sport Berbasis Content Management System (CMS) Joomla Modules VirtueMart. Jurnal Sisfotek Global, 7(2) , pp. 75-80. 2017. 